\title{
Ileal and colonic fatty acid profiles in patients with active Crohn's disease
}

\author{
S Bühner, E Nagel, J Körber, H Vogelsang, T Linn, R Pichlmayr
}

Clinic of Abdominal and Transplantation Surgery, Medical School, Hannover, Germany

$S$ Bühner

E Nagel

R Pichlmayr

Department of Gastroenterology, Rudolf Virchow Hospital, Berlin Germany

J Körber

\section{Department of} Gastroenterology, General Hospital, Vienna, Austria $\mathrm{H}$ Vogelsang

Department of Gastroenterology Medical Clinic III University of Gießen, Germany

T Linn

Correspondence to: Dr S Bühner, University Hospital Mannheim, Clinic of Gastroenterology, Department of Internal Medicine IV,

Theodor-Kutzer-Ufer 68167 Mannheim Germany.

Accepted for publication 9 February 1994

\begin{abstract}
In patients with active Crohn's disease and in a control group the fatty acid profiles in the whole lipid fraction of ileal and colonic mucosal biopsy specimens were determined by capillary gas chromatography. The biopsy specimens in Crohn's disease patients were taken from the inflamed terminal ileum as well as from the inflamed and macroscopically normal colon. Compared with controls the fatty acid distribution in the inflamed ileal mucosa was significantly characterised by (a) a decrease of 18:2 n6 and 18:3 n3 accompanied by a substantial increase of the highly polyunsaturated fatty acids 20:4 n6, 22:4 n6, and 22:6 n3 and (b) a higher unsaturation index of total fatty acids compared with controls. These changes were similar in the inflamed colon. Additionally, both the inflamed and the macroscopically normal colonic mucosa showed an increase of saturated (18:0) and a decrease of monounsaturated fatty acids (18:1 n9). Fatty acid profiles of ileum and colon showed side variations in controls, but not in the Crohn's disease group. These data suggest that in Crohn's disease changes in the distribution of polyunsaturated fatty acids seem to be the general feature of inflamed mucosa in small and large intestine. Results further suggest that colonic fatty acid metabolism in Crohn's disease is altered by degrees, showing changes in saturated and monounsaturated fatty acids as an additional, primary event.
\end{abstract}

(Gut 1994; 35: 1424-1428)

In inflammatory bowel disease (IBD) particular eicosanoids are increased in inflamed intestine. ${ }^{1-3}$ These substances have proinflammatory properties and derivate from an n6 fatty acid, the arachidonic acid (20:4 n6). Taking advantage of the competitive inhibition between $\mathrm{n} 6$ and $\mathrm{n} 3$ fatty acids, one therapeutic approach focuses on the modification of the eicosanoid synthesis by dietary supplementation with fish oils, which are rich in long chain highly polyunsaturated $\mathrm{n} 3$ fatty acids. ${ }^{45}$ Essential functions of polyunsaturated fatty acids in the gut, however, depend on their balance between $n 6$ and $n 3$ fatty acids ${ }^{6}$ and on their balance between saturated and unsaturated fatty acids. ${ }^{7}$ An important example is the control of membrane properties. ${ }^{67}$ This is one reason why the therapeutic use of high doses of $\mathrm{n} 3$ fatty acids is not undisputed.
Furthermore, for unknown reasons, clinical benefit seems to be confined to ulcerative colitis, ${ }^{8}$ which affects only the colon. In Crohn's disease, which may involve both small and large intestine, local fatty acid metabolism might be different.

Basic knowledge of fatty acid metabolism in patients with IBD is limited. Three recent studies showed changes in plasma fatty acid profile in patients with inactive ${ }^{910}$ and active IBD. ${ }^{11}$ Studies concerning the intestinal mucosa concentrate on ulcerative colitis. ${ }^{12}$ Data on Crohn's disease are limited to the colon and focus on particular fatty acids ${ }^{13}$ or the control state is omitted. ${ }^{814}$ Therefore the purpose of this study was a detailed assessment of the mucosal fatty acid profile of the terminal ileum and the colon in patients with Crohn's disease and in a control group. We were basically interested in characteristics and site variations of changes in inflamed areas. As another study shows that the metabolism of the 'quiescent' colon in IBD might already be altered, ${ }^{15}$ we additionally assessed the fatty acid profile of macroscopically normal colonic mucosa in patients with Crohn's disease.

\section{Methods}

PATIENTS

Studies were carried out on mucosal biopsy specimens, which were obtained from patients undergoing routine endoscopic examinations of the small and large bowel. Each patient gave informed consent.

Diagnosis for Crohn's disease $(n=15)$ was based on full clinical examination including endoscopy, histological examination of mucosal biopsy specimens, and radiographic examination; the first diagnosis was 2-19 years before the current examination. All patients had acute symptoms. Routine endoscopy showed inflammatory activity in the mucosa of the colon $(n=6)$, the terminal ileum $(n=4)$, or both $(n=5)$. Inflamed mucosa was reddened, friable, oedematous, and characterised by spontaneous bleeding, focal ulcerations, and aphthous lesions. Non of the patients had been surgically treated; 9 of 15 were receiving drug treatment (Table I).

The control group consisted of 16 women and men undergoing routine endoscopy for various diseases of the gastrointestinal tract (Table I). An acute or (present or past) chronic inflammation of the bowel was excluded on the basis of the complete anamnesis and the clinical parameters listed above. Non of the patients were suffering from acute diarrhoea. 
TABLE I Clinical features of the patients

\begin{tabular}{|c|c|c|}
\hline & Controls $(n=16)$ & Crohn's disease $(n=15)$ \\
\hline Age (y) & $45(18-75)$ & $38(19-65)$ \\
\hline $\operatorname{Sex}(\mathrm{F} / \mathrm{M})$ & $9 / 7$ & $9 / 6$ \\
\hline \multicolumn{3}{|l|}{ Diagnosis: } \\
\hline Crohn's disease & & $2-19$ years \\
\hline Without pathology & 3 & \\
\hline Rectum diverticula & 1 & \\
\hline Colon polypi & 2 & \\
\hline Haemorrhoids & 1 & \\
\hline Rectum carcinoma & 2 & \\
\hline Irritable bowel syndrome & 6 & \\
\hline Previous surgery & 0 & 0 \\
\hline \multicolumn{3}{|l|}{ Current drug treatment: } \\
\hline Untreated & 16 & 6 \\
\hline Corticosteroids only & & 1 \\
\hline 5-ASA only & & 2 \\
\hline Sulphasalazine only & & 1 \\
\hline Corticosteroids +5-ASA & & 2 \\
\hline Corticosteroids + sulphasalazine & & 3 \\
\hline \multicolumn{3}{|l|}{$\begin{array}{l}\text { Complications: } \\
\text { Cons }\end{array}$} \\
\hline Anal fistula & & 3 \\
\hline Perianal fistula & & 1 \\
\hline Dietary habits & Normal Western dict & Normal Western diet \\
\hline \multicolumn{3}{|l|}{ Sample localisations: } \\
\hline Ileum only & 6 & 4 \\
\hline Ileum + colon & 4 & 5 \\
\hline $\begin{array}{l}\text { Colon only } \\
\text { S }\end{array}$ & 6 & 6 \\
\hline Colon (macroscopically normal) & & 9 \\
\hline
\end{tabular}

There was no surgical pretreatment or current drug treatment in this group.

At the time of this study all patients lived at home and were receiving a normal, Western diet. The nutritional habits were obtained from a questionnaire. Subjects with: (a) greatly reduced food intake, (b) dietary regimens, such as diabetic or vegetarian diets, and (c) special dietary treatments including vitamin and fish oil supplements during the previous six months, were ruled out and not examined in this study. None of the patients excluded
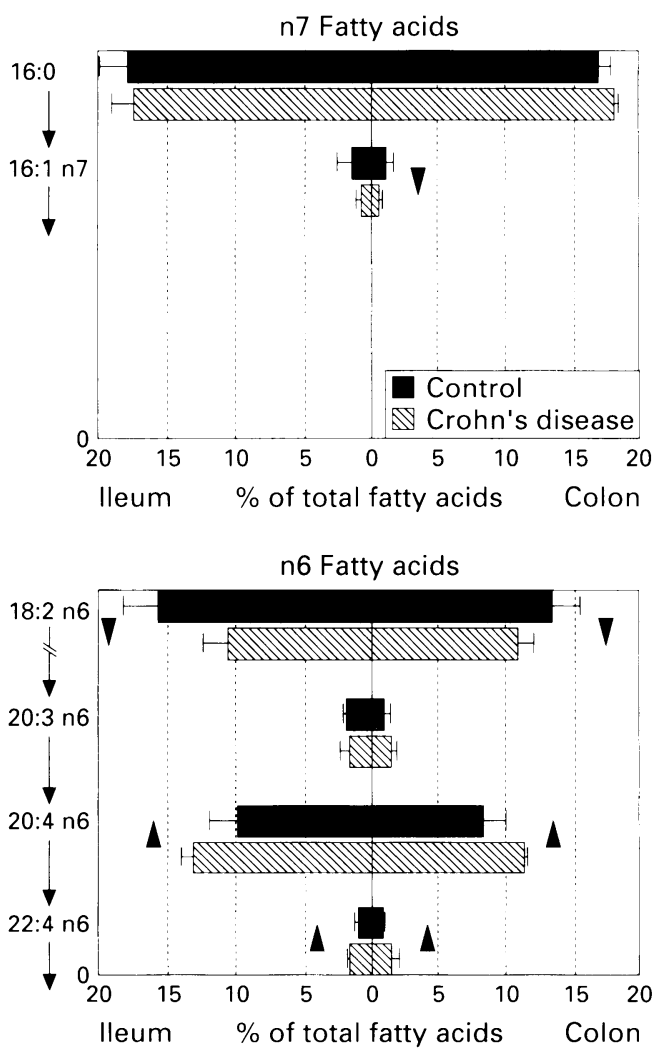

a particular dietary fat (such as a particular vegetable fat or animal fat) from their daily food.

ANALYSIS OF FATTY ACIIS

For fatty acid analysis one mucosal biopsy specimen was taken from each patient either at the terminal ileum $(5-10 \mathrm{~cm}$ proximal to the ileocaecal valve) or at the colon (left flexura) or at both sites (Table I). Control specimens had a normal mucosal appearance; in Crohn's disease these areas were inflamed. Additionally, specimens of endoscopically normal colonic mucosa were obtained from nine patients with Crohn's disease. A distance of at least $10 \mathrm{~cm}$ was maintained from any inflamed localisations in the colon $(n=6)$. The specimens were carefully washed and stored at $-80^{\circ} \mathrm{C}$.

For subsequent fatty acid analysis in the whole lipid fraction, samples were weighed (range: $10-15 \mathrm{mg}$ ), homogenised separately with liquid nitrogen in a mortar, and kept in $4 \mathrm{ml} 2: 1 \mathrm{chloroform} / \mathrm{methanol}(\mathrm{vol} / \mathrm{vol})$ at $4^{\circ} \mathrm{C}$ for 24 hours. After volume reduction in a nitrogen stream and addition of heptadecanoic acid methyl ester (C17:0) as internal standard, the samples were saponified overnight $\left(4^{\circ} \mathrm{C}\right)$ with $2.5 \mathrm{ml} \mathrm{90 \%} \mathrm{methanol} \mathrm{potassium} \mathrm{hydroxide}$ solution. Fatty acid methyl esters were prepared by boiling on reflux with $7.5 \mathrm{ml} 10 \%$ borontrifluoride-methanol-complex at $80^{\circ} \mathrm{C}$ for 20 minutes, fourfold extraction with hexane, drying on molecular sieves, and careful evaporation in the vacuum and with a nitrogen stream.
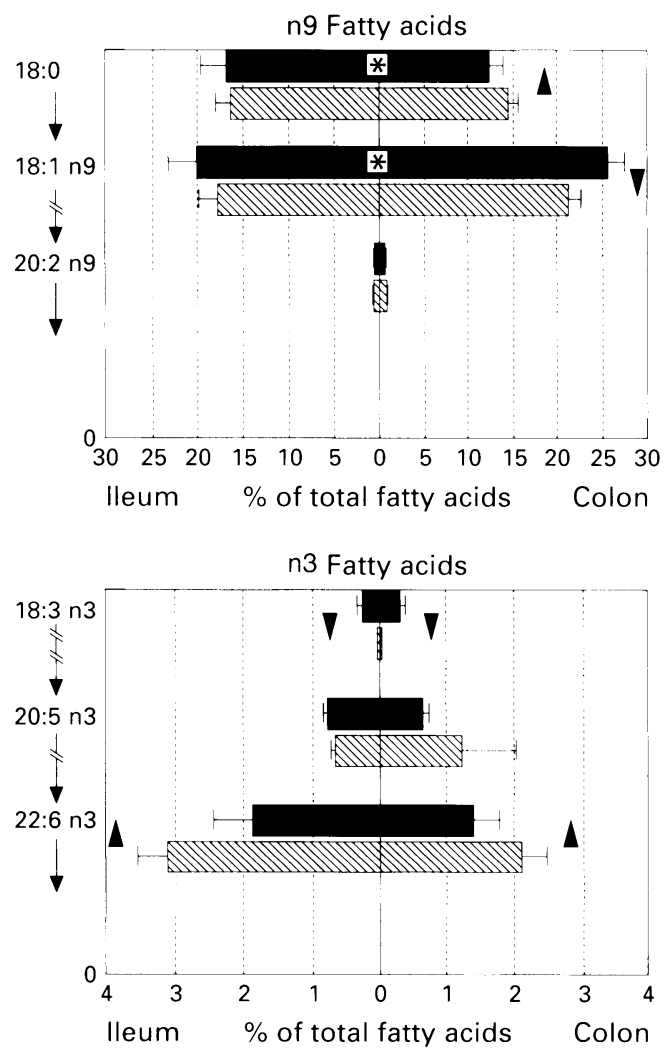

Figure 1: Fatty acid distribution in inflamed ileal and colonic mucosa in patients with Crohn's disease. Values are given as percentages of total fatty acids. Fatty acids are listed in the order of their metabolic pathway; =indicates a skipped step; ${ }^{\star}$ indicates differences between the ileum and the colon in the control group; $\boldsymbol{\Delta} \boldsymbol{\nabla}$ indicate differences between controls and Crohn's disease in either the ileum or the colon; $p<0.05$, Wilcoxon-Mann-Whitney test, mean (SD). 
TABLE II Fatty acids in inflamed ileal and colonic mucosa in patients with Crohn's disease

\begin{tabular}{|c|c|c|c|c|}
\hline & \multicolumn{2}{|l|}{ Ileum } & \multicolumn{2}{|l|}{ Colon } \\
\hline & Control & Crohn's disease & Control & Crohn's disease \\
\hline 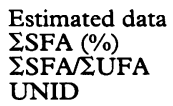 & $\begin{array}{c}35.9(4.0)^{\star} \\
0.6(0.1)^{\star} \\
126(6) \dagger\end{array}$ & $\begin{array}{c}36 \cdot 1(2 \cdot 7) \\
0 \cdot 6(0 \cdot 1) \\
142(11)\end{array}$ & $\begin{array}{c}31.1(1.5) \\
0.4(0.03) \\
116(8) \dagger\end{array}$ & $\begin{array}{c}33.3(2 \cdot 7) \\
0.5(0 \cdot 1) \\
133(5)\end{array}$ \\
\hline
\end{tabular}

Values of fatty acids (FA) are calculated as percentage of total FA.

*Indicates differences between ileum and colon in the control group; $\dagger$ indicates differences between controls and Crohn's disease in either the ileum or the colon; $p<0.05$, WilcoxonMann-Whitney test, mean (SD). SSFA: sum of saturated FA; $\Sigma$ UFA: sum of unsaturated FA; UNID: $\Sigma$ (FA percentage $\times$ number of double bonds).

The residue was dissolved in $200 \mu$ l heptan and submitted to fatty acid measurements with a 5890 Hewlett Packard gas chromatograph using nitrogen as carrier gas (pressure: $16 \mathrm{psi}$ ). It was equipped with a flame ionisation detector and a $50 \mathrm{~m} \times 0.22 \mathrm{~mm}$ internal diameter capillary column (CP SIL88, Chrompack, Frankfurt, Germany). Initial oven temperature was $60^{\circ} \mathrm{C}$ for one minute followed by heating periods of $20 \% \mathrm{~min}$ up to $180^{\circ} \mathrm{C}$ and $5 \% \mathrm{~min}$ to reach the final temperature of $200^{\circ} \mathrm{C}$; the injector and detector temperatures were set at $250^{\circ} \mathrm{C}$ and $270^{\circ} \mathrm{C}$, respectively.

Fatty acids (C14:0-22:6 n3) were identified using standards (Sigma, Deisenhofen, Germany) and their portion in the samples was determined as a percentage of total fatty acid (wt/wt).

\section{STATISTICS}

Data were presented as mean (SD), whereby data from similar sites in each patient group were added. They were checked for significant differences using the Wilcoxon-MannWhitney test with a probability value of $\mathrm{p}<0.05$.

\section{Results}

The mucosal fatty acid profile of the inflamed terminal ileum in patients with Crohn's disease compared with controls was basically characterised by significant changes in the distribution of polyunsaturated fatty acids

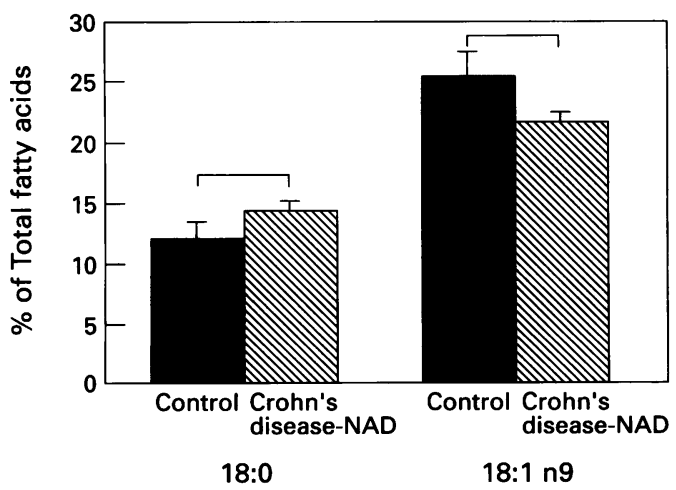

Figure 2: Macroscopically normal (NAD: no abnormality discovered) colonic areas of patients with Crohn's disease were characterised by a higher percentage of 18:0 and $a$ lower percentage of 18:1 compared with controls, $\square$ $p<0.05$, Wilcoxon-Mann-Whitney test. The distribution of other fatty acids was unaltered, mean (SD).
(Fig 1). In the series of n6 fatty acids, a decrease of the essential linoleic acid (18:2 n6) was accompanied by an increase of highly polyunsaturated desaturation and elongation products, arachidonic acid (20:4 n6) and docosatetraenoic acid (22:4 n6). A similar pattern was obvious in the series of the $n 3$ fatty acids showing a decrease of $\alpha$ linolenic acid (18:3 n3) and an increase of docosahexaenoic acid (22:6 $\mathrm{n} 3)$ percentages. The proportions of dihomo- $\gamma$-linolenic acid (20:3 n6), eicosapentaenoic acid (20:5 n3) of the individual series, and the proportion of the $\mathrm{n} 9$ fatty acid eicosadienoic acid (20:2 n9) varied only slightly between the control group and the patients with Crohn's disease. The ratio of saturated and unsaturated fatty acids in the mucosa was unaffected by the current inflammation (Table II). In contrast, the unsaturation index, taking into account the number of double bonds of the particular fatty acid, increased compared with controls.

So far the results in the inflamed colon confirmed the findings in the terminal ileum. The colonic fatty acid profile in Crohn's disease was, however, additionally characterised by an increase of saturated fatty acids (stearic acid (18.0)) and a decrease of monounsaturated fatty acids (palmitoleic acid (16:1 n7), oleic acid (18:1 n9)) compared with controls (Fig 1). Therefore the sum of saturated fatty acids as well as the ratio of saturated and unsaturated fatty acids tended to increase (Table II). A similar change of $\mathrm{C} 18$ saturated and monounsaturated fatty acids was already obvious in macroscopically normal colonic sites of patients with Crohn's disease (Fig 2). The distribution of polyunsaturated fatty acids in these sites, however, did not differ significantly from that in controls.

Differences between the fatty acid profiles of small and large intestine occurred only in the control group, being characterised by a lower percentage of 18:0 and a higher percentage of 18:1 $\mathrm{n} 9$ in the colon (Fig 1). Accordingly, the sum of saturated fatty acids and the quotient of saturated and unsaturated fatty acids were lower in colonic than in ileal mucosa (Table II).

A small percentage of structurally altered transisomeric fatty acids was found in all mucosal samples. The percentage of elaidinic acid, the most common 18:1 n9 transisomer, was on average $0.8 \%$ of total fatty acids, showing no differences between controls and Crohn's disease or local differences.

The current drug treatment in Crohn's disease had no significant effects on the proportions of esterified fatty acid in the ileum or the colon. An example is given for ileal 20:4 n6: untreated patients $(n=3) 12 \cdot 3(1 \cdot 8) \%$, treated patients $(n=6) 13.3(1.9) \%$ and colonic 20:4 n6: untreated patients $(n=5) 12 \cdot 7(2 \cdot 2) \%$, treated patients $(n=6) 10 \cdot 4(1 \cdot 8) \%$.

\section{Discussion}

In active Crohn's disease the fatty acid profiles of both inflamed ileal and colonic mucosa are 
basically characterised by a change in distribution of $n 3$ and $n 6$ polyunsaturated fatty acids compared with controls. Changes in the proportions of saturated and monounsaturated fatty acids are an additional feature but limited to colonic mucosa. It is most likely that these differences derive from the current inflammatory disease. Firstly, the nutritional recordings did not provide evidence of any significantly different dietary fat intake in the two patient groups. This is important because dietary fats are known modulators of intestinal fatty acid distribution. ${ }^{716}$ Secondly, patients with Crohn's disease could suffer from essential fatty acid deficiency. The typical fatty acid pattern, however, indicating this status (decrease of $n 6$ and increase of $n 9$ fatty acids ${ }^{17-19}$ ) was not obvious in this group. Thirdly, the current drug treatment in Crohn's disease patients did not significantly influence the proportion and distribution of esterified fatty acids in ileal and colonic mucosa. This is in agreement with findings in the rectum. ${ }^{13}$ It is known that these drugs do influence the fatty acid metabolism, but this may concentrate on free, but not on esterified fatty acids, as shown for arachidonic acid. 2021

Profound changes of polyunsaturated fatty acids similarly characterised the large and small intestine in Crohn's disease and might be regarded as a general feature of the chronically inflamed areas. Regarding the pattern of changes it is striking that an increase of long chain polyunsaturated $\mathrm{n} 3$ and $\mathrm{n} 6$ fatty acids is combined with a decrease of the individual essential precursors - that is, 18:2 $\mathrm{n} 6$ and 18:3 n3. This would suggest an enhanced local biosynthesis of long chain polyunsaturated fatty acids or a substitutive incorporation of fatty acids. This second mechanism is known in the regulation of structural-functional homoeostasis of membranes. ${ }^{1922}$ Evidence of both mechanisms is provided by studies in rats. ${ }^{22} 23$ To clarify this finding, however, it is necessary to define the mucosal compartments or cell types, which are the predominant site of changes in individual fatty acids and to elucidate their metabolic interactions. The change in the fatty acid profile led to an increase of the unsaturation index in the inflamed mucosa. This might contribute to the enhanced intestinal permeability in patients with Crohn's disease. ${ }^{24-26}$

In detail, this study showed a considerable increase of esterified 20:4 $\mathrm{n} 6$ in the inflamed areas. This confirms findings in the rectum of patients with Crohn's disease. ${ }^{13}$ As repeatedly supposed, this may be directly related to the increase of the individual eicosanoid derivates in the mucosa of patients with Crohn's disease. ${ }^{1-3}$ The proportions of 20:3 n6 and 20:5 n3, which are known precursors of other eicosanoids, ${ }^{27}$ did not differ between controls and Crohn's disease. They may therefore play a minor part in the pathomechanism of the disease. The increase of 22:6 n3 is interesting, as high concentrations are also reported in the plasma of IBD patients. ${ }^{11}$ There is still little knowledge about the biological activity and role of 22:6 $\mathrm{n} 3^{28}$ in the intestine. Recently an in vitro study reported an inhibition of mammalian prostaglandin synthetase by 22:6 n3. ${ }^{28}$ It could be cautiously speculated that the high proportion might therefore have a regulative implication. This point needs detailed in vivo analysis, however, especially to be certain of the validity of a further increase of 22:6 $\mathrm{n} 3$ by supplementation with fish oils in the treatment of IBD.

Changes in the distribution of saturated and monounsaturated fatty acids also occurred in the patients with Crohn's disease, but this was only a feature of the colon not of the terminal ileum. It was basically an increase of 18:0 and decrease of 18:1 n9 proportions compared with controls. The changes led to an alignment of ileal and colonic fatty acid profiles in patients with Crohn's disease, which contrasts with the findings in the control group. It would be interesting to discover if this is followed by a functional alignment. These findings suggest site variations between the small and large intestine in specific fatty acid incorporation or intestinal $\Delta 9$ desaturase activity in response to pathophysiological signals. Studies in rats provide evidence of such mechanisms, showing intestinal site variations in these parameters during fasting or different dietary fat composition. ${ }^{2329}$ However, information in humans is rare. A most striking finding was that these individual colonic changes were not limited to the inflamed areas, but were already seen in macroscopically normal colon in patients with active Crohn's disease. The distribution of polyunsaturated fatty acids remained unchanged. This suggests that colonic fatty acid metabolism in Crohn's disease is altered by degrees, showing changes in saturated and monounsaturated fatty acids as a primary step. It supports the concept that the 'quiescent' mucosa in Crohn's disease is not at all quiescent, as already reported for morphological parameters. ${ }^{30}$ This corresponds with recent findings in Crohn's disease indicating that quiescent mucosal cells of the colon are somehow primed for a rapid change of metabolism. ${ }^{15}$

The changes in colonic fatty acid profile do not seem to be specific for Crohn's disease as our data show clear similarities to those ascertained for the inflamed colon in ulcerative colitis. ${ }^{12}$ Variations (concerning the proportions of 18:2 n6 and 18:3 n3) might result from the fact that in ulcerative colitis the analysis focused only on the phospholipid fraction of mucosal fat.

Additionally, we checked the mucosal fatty acid profiles for the presence of structurally altered transisomeric fatty acids, because it has been suggested that these fatty acids play a part in the pathogenesis of Crohn's disease. ${ }^{30} 31$ Their proportion in the adipose tissue of patients with Crohn's disease was found to be unusually high. ${ }^{30}$ According to our results, this is not the case in the intestinal mucosa. Therefore it has to be assumed that in our patient group the consumption of dietary fats containing these fatty acids was not actually increased.

When comparing these results with recently 
published data on plasma fatty acid profile in inactive $^{9}$ and active Crohn's disease, ${ }^{11}$ it is seen that apart from one fatty acid (22:6 n3) the changes of the fatty acid distribution in the plasma counteracted the developments in the intestinal mucosa. This clearly shows that plasma fatty acid composition in IBD did not reflect tissue composition, as was recently stated. ${ }^{11}$ The two compartments obviously react differently to disease dependent signals in the organism. It is difficult to draw conclusions, however, on the metabolic flux based on the fatty acid patterns alone. In this context recent studies in rats stress the importance of enzymatic assays of the fatty acid pathway. Their findings strongly suggest, for example, that liver and intestinal desaturase enzymes respond differently to changes in physiological conditions such as fasting or dietary n3 fatty acid intake. ${ }^{23} 32$ It would be an advance to elucidate such mechanisms for the pathophysiological condition of IBD especially in terms of dietary fat treatment in these patients.

This study showed profound changes of ileal and colonic fatty acid profiles in active Crohn's disease. Thereby changes in polyunsaturated fatty acids seem to be a general feature of inflamed areas while changes in saturated and monounsaturated fatty acids are limited to the colon but already involve the so called 'quiescent' areas. This work was supported by the Deutsche
Forschungsgemeinschaft, grant NA 184/1-2.

Part of these data were presented at the 1 st congress of the International Society for the Study of Fatty Acids and Lipids, June 1993, Lugano, Switzerland; the proceedings will be published by Karger, Basle, Switzerland.

The authors gratefully acknowledge the critical comments by Dr Jürgen Westermann (Centre of Anatomy, Medical School Hannover), the help in providing biopsy specimens by Andrea Brichta, the technical assistance of Uta Frommknecht-Reddig, and help with English by Sheila Fryk.

1 Donowitz M. Arachidonic acid metabolites and their role in inflammatory bowel disease. Gastroenterology 1985; 88: $580-7$

2 Hawkey CJ, Rampton DS. Prostaglandins and the gastrointestinal mucosa: are they important in its functions, disease or treatment? Gastroenterology 1985; 89: 1162-88.

3 Lauritsen K, Laursen LS, Bukhave K, Rask-Madsen J. In vivo profiles of eicosanoids in ulcerative colitis, Crohn's colitis, and clostridium difficile colitis. Gastroenterolog 1988; 95: 11-7.

4 Fischer S, Weber PC. Prostaglandin I3 is formed in vivo in man after dietary eicosapentaenoic acid. Nature 1984, 307: $165-8$.

5 Lee TH, Hoover RL, Williams JD, Sperling RI, Ravalese III $\mathrm{J}$, Spur BW, et al. Effect of dietary enrichment with eicosapentaenoic and docosahexaenoic acids on in vitro neutrophil and monocyte leukotriene generation and neutrophil function. $N$ Engl $\mathcal{F}$ Med 1985; 312: 1217-24. neutrophil function. $N$ Engl f Med 1985; 312: 1217-24. polyunsaturated fatty acids in man. An overview of still unresolved and controversial questions. Experientia 1991; 47: $172-8$.

7 Clandinin MT, Cheema S, Field CJ, Garg ML, Venkatraman J, Clandinin TR. Dietary fat: exogenous determination of membrane structure and cell function. FASEB F 1991; 5: 2761-9.

8 Lorenz R, Weber PC, Szimnau P, Heldwein W, Strasser T, Loeschke K. Supplementation with n-3 fatty acids from fish oil in chronic inflammatory bowel disease - a randomized, placebo-controlled, double-blind cross-over trial. F Intern Med 1989; 225: 225-32.

9 Brendinger $M$, Vogelsang $H$, Lochs $H$, Widhalm $K$ Atypisch verändertes Fettsäuremuster der Serumlipide von Patienten mit inaktivem M. Crohn. Infusionstherapie 1991; 18: 50 .
10 Esteve-Comas $M$, Núñez $M C$, Fernández-Bañares $F$ Abad-Lacruz A, Gil A, Cabré E, et al. Abnormal plasma polyunsaturated fatty acid pattern in non-active inflammatory bowel disease. Gut 1993; 34: 1370-3.

11 Esteve-Comas $M$, Ramírez $M$, Fernández-Bañares $F$, Abad-Lacruz A, Gil A, Cabré E, et al. Plasma polyunsaturated fatty acid pattern in active inflammatory bowe disease. Gut 1992; 33: 1365-9.

12 Nishida T, Miwa H, Shigematsu A, Yamamoto M, Iida M Fujishima $\mathbf{M}$. Increased arachidonic acid composition of phospholipids in colonic mucosa from patients with active ulcerative colitis. Gut 1987; 28: 1002-7.

13 Pacheco S, Hillier K, Smith C. Increased arachidonic acid levels in phospholipids of human colonic mucosa in inflammatory bowel disease. Clin Sci 1987; 73: in inflam.

14 Hillier K, Jewell R, Dorrell L, Smith CL. Incorporation of fatty acids from fish oil and olive oil into colonic mucosal lipids and effects upon eicosanoid synthesis in inflammaory bowel disease. Gut 1991; 32: 1151-5.

15 Wardle TD, Hall L, Turnberg LA. Use of coculture of colonic mucosal biopsies to investigate the release of eicosanoids by inflamed and uninflamed mucosa from patients with inflammatory bowel disease. Gut 1992; 33: 1644-51.

16 Bühner S, Nagel E, Stockhorst H, Körber J, Sagredos AN, Pichlmayr R. Influence of heated and non-heated partially hydrogenated dietary fats on the ileal chyme fat and the fatty acid composition of ileal mucosa in pigs. Dig Dis $S c i$ (in press)

17 Paulsrund JR, Pensler L, Whitten CF, Stewart S, Holman RT. Essential fatty acid deficiency in infants induced by RT. Essential fatty acid deficiency in infants induced by fat-free in $897-904$.

18 Hill EG, Johnson SB, Lawson LD, Mahfouz MM, Holman RT. Perturbation of the metabolism of essential fatty acids by dietary partially hydrogenated vegetable oil. Proc Natl Acad Sci 1982; 79: 953-7.

19 Duranthon V, Frémont L, Léger CL. Effect of essentia fatty acid deficiency on lipid composition of basolateral plasma membrane of pig intestinal mucosal cells. Lipid 1991; 26: 175-81.

20 Flower RJ, Blackwell GJ. Anti-inflammatory steroids induce biosynthesis of a phospholipase A2 inhibitor which prevents prostaglandin generation. Nature 1979; 278: prevents.

21 Gustafson C, Sjödahl R, Tagesson C. Phospholipase activa tion and arachidionic acid release in intestinal epithelial cells from patients with Crohn's disease. Scand $f$ Gastroenterol 1990; 25: 1151-60.

22 Gibson RA, McMurchie EJ, Charnock JS, Kneebone GM. Homeostatic control of membrane fatty acid composition in the rat after dietary lipid treatment. Lipids 1984; 19 942-51.

23 Garg ML, Keelan M, Thomson ABR, Clandinin MT Desaturation of linoleic acid in the small bowel is increased by short-term fasting and by dietary content of linoleic acid. Biochim Biophys Acta 1992; 1126: $17-25$

24 Teahon K, Smethurst P, Pearson M, Levi AJ, Bjarnason I. The effect of elemental diet on intestinal permeability and inflammation in Crohn's disease. Gastroenterology 1991; 101: 84-9.

25 Adenis A, Colombel J-F, Lecouffe P, Wallaert B, Hecquet $\mathrm{B}$, Marchandise X, et al. Increased pulmonary and intestinal permeability in Crohn's disease. Gut 1992; 33: 678-82.

26 Wyatt J, Vogelsang H, Hübl W, Waldhör T, Lochs $H$. Intestinal permeability and the prediction of relapse in Crohn's disease. Lancet 1993; 341: 1437-9.

27 Crawford MA. Background to essential fatty acids and their prostanoid derivatives. Br Med Bull 1983; 39: 210-3.

28 Corey EJ, Shih C, Cashman JR. Docosahexaenoic acid is a strong inhibitor of prostaglandin but not leukotriene biosynthesis. Proc Natl Acad Sci USA 1993; 80: 3581-4.

29 Garg ML, Keelan M, Wierzbicki A, Thomson ABR Clandinin MT. Regional differences in lipid composition and incorporation of saturated and unsaturated fatty acids into microsomal membranes of rat small intestine. Can $\mathcal{F}$ into microsomal membranes of rat small

30 Nagel E, Pichlmayr R. Animal experiments in inflammatory bowel diseases. In: Jeppson B, ed. Animal modelling in surgical research. Stuttgart: Thieme (in press)

31 Heckers H, Melcher FW, Kamenisch W, Henneking K Chemisch aufbereitetes Fett und Morbus Crohn Eine Pilotstudie zum Vorkommen von trans-Fettsäuren im Unterhautfettgewebe von Crohn-Patienten im Vergleich mit gesunden Kontollen als Parameter des Langzeitfettverzehrs. $Z$ Gastroenterol 1988; 26: 259-64.

32 Garg ML, Keelan M, Thomson ABR, Clandinin MT. Intestinal microsomes: polyunsaturated fatty acid metabolism and regulation of enterocyte transport properties. Can f Physiol Pharmacol 1990; 68: 636-41. 